\title{
A Promising Optical-Acoustic Method for Measuring the Marine Environment Thermodynamic State Parameters. Error Assessment
}

\author{
V.I. Babiy ${ }^{1}$, M.V. Babiy ${ }^{1}$, A.A. Rodionov ${ }^{2}$ \\ ${ }^{1}$ Marine Hydrophysical Institute, Russian Academy of Sciences, Sevastopol, \\ Russian Federation \\ e-mail: marbab@yandex.ru \\ ${ }^{2}$ Saint-Petersburg Branch of the P.P. Shirshov Institute of Oceanology, \\ Russian Academy of Sciences, Saint-Petersburg, \\ Russian Federation \\ e-mail: sppp@spbrc.nw.ru
}

\begin{abstract}
A concept of constructing a perfect hydrophysical meter of thermodynamic state parameters of the randomly inhomogeneous fluid is the basis of the proposed method. The concept represents continuous simultaneous measurements of the light refractive index, the sound velocity and the pressure in a single volume of marine environment. The errors of direct and indirect measurements of the marine environment thermodynamic state parameters are estimated. A possible variant of opticalacoustic meter implementation is proposed. The problem of decentralization of the standard base of such meters by creating a single special primary standard of sound velocity and light velocity units in transparent fluids with the reference to the perfect easily-reproduced absolute rapper (light velocity in a vacuum) accepted as the world fundamental physical constant is considered.
\end{abstract}

Keywords: seawater, state parameters, light velocity, sound velocity, pressure, quasi-perfect meter, measurement errors, single standard, decentralization.

DOI: 10.22449/1573-160X-2016-2-62-72

(c) 2016, V.I. Babiy, M.V. Babiy, A.A. Rodionov

(C) 2016, Physical Oceanography

Introduction. Almost all the information on ocean hydrophysical fields, their structure and spatio-temporal variability was gained from field measurements. Direct measurement methods are absolutely favored over the indirect ones at that. However, the most important primary parameters of marine environment thermodynamic state (density and salinity) currently can't be measured by in situ direct method with the necessary accuracy, fast response and reliability due to the absence of such measuring means. These parameters are calculated by the results of temperature, conductivity and pressure direct measurements carried out by traditional hydrological CTD-probes [1 - 7]. Practically unavoidable errors, which occur during dynamic measurements of state parameters in randomly inhomogeneous and non-stationary marine environment, are the fundamental disadvantages of all modern CTD-probes. The disadvantages are caused by the difference of volumes of hydrophysical field averaging carried out by sensors, their different orientation and spacing in environment, unequal response time of channels and their noises. These effects may be weakened partially by some means when performing the subsequent mathematical processing of CTD-data [7]. The problem of indirect measurement correctness in hydrophysics is not solved yet, despite the fact that it had arose a long time ago.

Correct precision measurements of parameters of marine environment thermodynamic state is a complex problem which includes the following interrelated aspects: measurement principles and conditions, measurement 
techniques and graduations, sensor interaction with measurement object (environment), the structure of hydrophysical fields under study and the objective of research, seawater state equations, techniques of mathematical processing, analysis and interpretation of measurement results, assessment of reconstruction errors, etc. In randomly inhomogeneous media, including the oceanic one, it is also a problem of dynamic measurement correctness. It should be pointed out that all these aspects of hydrophysical measurements are studied only within the framework of approximate mathematical models.

Let us consider a possible way of concept implementation of quasi perfect meter of the marine environment thermodynamic state parameters on the basis of optical-acoustic method which has no the considered disadvantages of contemporary CTD-probes.

The basis of the method. Seawater is a complex multicomponent thermodynamic system. When we describe its composition in a macroscopic way, it is characterized by mass (or volume) concentration of each $a_{i}$ component:

$$
\sum_{i=1}^{m} \boldsymbol{a}_{i}=1
$$

where $m$ is a number of components. Particularly, $a_{i}$ components may correspond to concentrations of different salts, diverse impurities (including seawater pollutants) that define its ecological characteristics. Seawater model complexity or a number of $m$ components under consideration depends on required accuracy and details of its investigation as a thermodynamic system. According to the Gibbs' phase rule, the number of independent variables (of thermodynamic degrees of freedom), required and sufficient for complete description of $l$-phase and $\mathrm{m}$ component equilibrium thermodynamic system state, is equal to $k=m-l+2$. In single-phase system $(l=1)$ we have $k=m+1$. For pure liquids, e.g. distilled water, $m=1, k=2$. In fact, the number of $k$ available for direct in situ measurements with required accuracy of seawater state parameters is limited. The specifics of marine environment research lies in the fact that the most important parameters of its state (density (or specific volume) and salinity) are not measured by direct in situ methods. These parameters are calculated on the basis of other (directly measured) ones which are functionally related to them. Currently three $(k=3)$ state parameters are directly in situ measured by hydrologic CTD-probes: temperature $(T)$, conductivity $(\chi)$ and hydrostatic pressure $(P)$. The seawater binary model "distilled water + quasi homogeneous salt", where $m=2$, is applied in oceanography within the framework of hypothesis of relative chemical composition constancy.

The required environment parameters are calculated by directly measuring $T, \chi$, $P$ on the basis of relevant equations of state. These parameters are the following: salinity $(S)$, density $(\rho)$, compressibility $(\beta)$, sound velocity $(C)$, light refraction index (n), etc. The most studied equations are $\rho=\rho(T, S, P)$ and its modifications $\rho=$ $=\rho(T, \chi, P), S=S(T, \chi, P)$ etc., where $S=a_{1}$. Relative error of indirectly measured state parameter determination makes up $\sim 10^{-5}-10^{-4}$. The increase of only $T, \chi, P$ direct measurement accuracy will not result in increase of determination accuracy of indirectly measured $\rho$ and $S$ parameters due to the error (limited approximately at $10^{-5}$ level) of existing empirical equations of state with $m=2$. These equations don't take into account regional peculiarities of the basin, e.g. the 
presence of hydrogen sulphide in the Black Sea. The further progress is possible due to the complication of seawater model, i.e. the increase of $m$. However, additionally to $T, \chi, P$, in situ with required accuracy measurements performing by the direct method are possible only for two more parameters: $C$ and $n$ (or for the light velocity $C_{l}$ ). Then we will obtain $k=5, m=4$. This will result in the error reduction of indirectly measured hydrophysical parameter calculation and improvement of state equations. Additional information can be obtained by consideration of $C, \chi, n$ parameter complex character and usage of their frequency dependence on $a_{i}$ components which is equivalent to the increase of $k$ and, consequently, $m$. For instance, the direct measurements of ultrasonic absorption parameter and frequency dependence $C$ as well as the measurements of $n$ and optical absorption coefficient at different light wavelengths will also allow us to increase $m$ and to improve the parameters of state. In this case, for measurement correctness it is desirable to carry out the compatibility of equal spatial averaging volumes of all the initial measuring transmitters. When performing the field investigations of marine environment as a non-equilibrium thermodynamic system, the most important meter characteristic (along with a spatial averaging volume) is a fast response.

$T$, $S$-analysis of water masses is extensively used in oceanology [1 - 3]. Binary system experimental research will be effective if we measure the parameters, which form the family of orthogonal isolines [2] at $T, S$-diagram, by the direct method. The position of some point on the diagram characterizing the seawater thermodynamic state in the presence of measurement errors will be most the certain in this case. An indicator of the isoline coordinate grid proximity to the orthogonal one is the following expression:

$$
\varepsilon=\iint_{T S} \psi(T, S) C(T, S) C_{\ell}(T, S) d T d S,
$$

where $\psi(T, S)$ is a weight function; the integration is carried out in some domain of $\mathrm{T}$ and $\mathrm{S}$ primary parameter variation. With the full orthogonality $\varepsilon=0$.

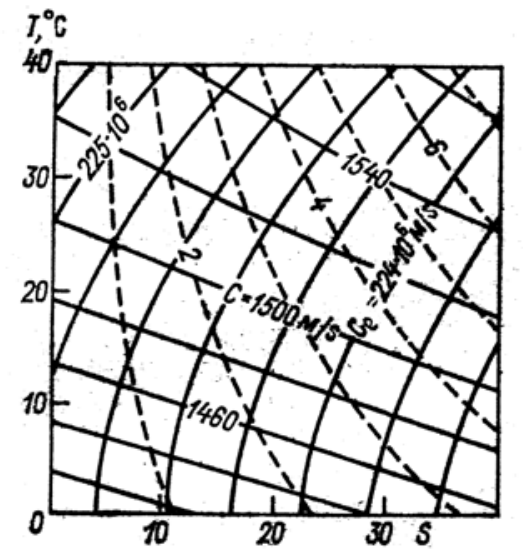

$a$

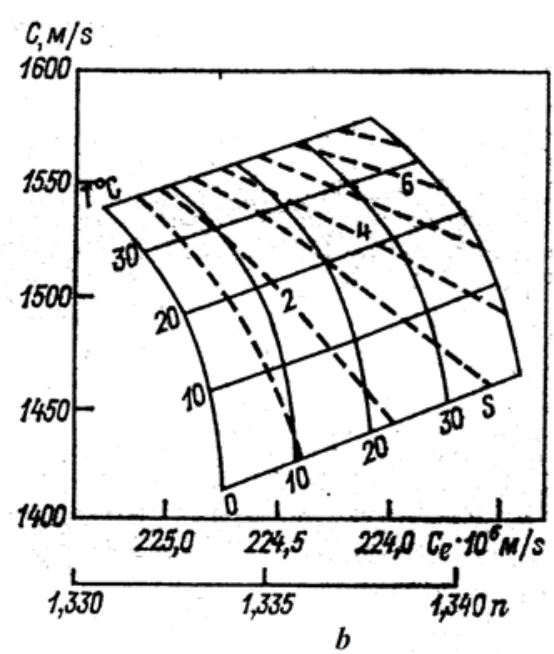

$b$

Fig. 1. Isoline families: $a-C, C_{l}, \chi\left(\mathrm{Sm} / \mathrm{m}\right.$, dashed lines) at $T, S$-diagram; $b-T, S, \chi$ at $C, C_{l}$-diagram 
In Fig 1 the families of state parameter isolines are represented at $P=P_{0}$ in two coordinate systems: $T, S$ and $C, C_{l}$ (or $C, n$ ) which have one-to-one correspondence with each other. As is evident, only $C, C_{l}$ and $C, n$ isoline systems are the most close to orthogonal ones unlike the $\chi$ (dashed lines) specific conductivity isolines. Accordingly, the $T, S$ isoline system at $C, C_{l}$-diagram is also close to the orthogonal one. This means that seawater thermodynamic state within the framework of a binary model is determined most reliably by measurements of light velocity (refraction index), sound velocity and hydrostatic pressure by synchronous measurements in unified volume of environment.

The above-mentioned disadvantages of CTD-probes can be removed almost completely in the probes with compatible primary measuring transducers [8 - 19] where the spatial and temporal averaging functions are separated, the measurements are synchronous, the functions of temporal averaging in the channels are similar and the volumes of hydrophysical field averaging are equal and combined (unified). The main advantage of compatible hydrophysical meters in comparison with traditional CTD-systems consists in the replacement of environment interaction with sensor substance by environment interaction with the radiation (acoustic (ultrasonic) and optical (laser)) in unified volume of environment, just like in parametric systems. This reduces dynamic errors that occur during the indirect measuring of temperature, density, salinity, compressibility and other state parameters based on direct measurements of the sound velocity and the light velocity. This takes place due to the fact that the velocities of light and acoustic wave propagation in the environment are high enough in comparison with hydrophysical field evolution rate $(\sim 1 \mathrm{~cm} / \mathrm{s},[2])$. This increases temporal resolution (fast response) of such meters and it is particularly important when carrying out dynamic measurements $[6,16]$.

The advantage of the given concept of quasi-perfect hydrophysical meter construction is the elimination of specific errors caused by spatial diversity and orientation of sensors with different volumes of temporal and spatial averaging. This makes correct the indirect measurements of other state parameters, based on direct measurements of sound velocity, light velocity (refraction index) and pressure. In this case, instead of contact (surface) marine environment interaction with a sensor substance (e.g. thermometer) the volumetric environment interaction with the optical and acoustic fields (which practically don't disrupt the structure of hydrophysical fields under study) is used. The interaction of these radiations with the environment (continuum) takes place at the atomic and molecular levels in a unified volume of environment and this allow us to bring closer the implementation of conception of perfect marine environment state parameter meter.

The hardware functions of hydrophysical field spatial and temporal averaging in such meter can be separated because the averaging takes place in different links of measuring chain:

$$
H_{i}\left(\xi_{1}, \xi_{2}, \xi_{3}, \tau\right)=H_{i}\left(\xi_{1}, \xi_{2}, \xi_{3}\right) H_{i}(\tau),
$$

where $H_{i}\left(\xi_{1}, \xi_{2}, \xi_{3}\right)$ is a weight function of $x_{i}$ element field spatial averaging carried out by $i$ sensor; $\xi_{1}, \xi_{2}, \xi_{3}$ are the spatial shifts; $\tau$ is a temporal shift; $H_{i}(\tau)$ is a weight function of temporal averaging carried out by $i$ measuring channel. In compatible meters $H_{i}\left(\xi_{1}, \xi_{2}, \xi_{3}\right)$ functions for all channels should be the same. PHYSICAL OCEANOGRAPHY NO. 2 (2016) 
Equivalent meter has the smallest error and the same functions of spatial averaging (identical spatial resolution) for all directly and indirectly measured state parameters with fully compatible volumes of spatial averaging carried out by sensors of directly measured parameters. This combination is best achieved in optical-acoustic meters of marine environment thermodynamic state parameters $[12,19]$. Temporal averaging functions $H_{i}(\tau)$ should also be the same for all channels and it can be easily done during the digital filtering [16].

In experimental studies of randomly inhomogeneous liquids (particularly, the studies of marine environment as non-equilibrium thermodynamic system) the dynamic parameter of $V_{0}=l_{0} / \tau_{0}$ (where $l_{0}$ is an effective scale of hydrophysical field spatial averaging performed by the sensor in the direction of probing trajectory, this scale is determined by $H_{i}\left(\xi_{1}, \xi_{2}, \xi_{3}\right)$ weight function; $\tau_{0}$ is an effective scale of temporal averaging performed by measuring channel in unit sample, the scale is determined by $H_{i}(\tau)$ function characterizing fast response, i. e. the temporal resolution [20]. Generalized $V_{0}$ parameter of hydrophysical measuring instruments (HPMI) is an index of the dynamic properties of any HPMI (the dimension velocity is $\mathrm{m} / \mathrm{s}$ ) which does not depend on operating principle and type of measured physical quantity. It characterizes the ability of all HPMI to carry out the correct measurements while the mobile carrier is moving [20]. Consequently, generalized $V_{0}$ parameter indicates the carrier velocity limit (relative to the environment) at which the correctness condition of small-scale measurements is still fulfilled. For instance, with $l_{0}=0.1 \mathrm{~m}$ and $\tau_{0}=0.01 \mathrm{~s}$ we obtain $V_{0}=10 \mathrm{~m} / \mathrm{s}$ ( 20 knots). In the compatible optical-acoustic meter $V_{0}$ dynamical parameter is the same for all the directly and indirectly measured environment state parameters, and this corresponds to the perfect HPMI concept.

In $[6,17]$ the method errors, arising from incomplete compatibility and difference of dimensions and orientation of spatial averaging carried out by instantaneous optical-acoustic meters of seawater state parameters, are considered using the mathematical simulation. When analyzing the errors, $y_{v}=\mathrm{F}\left(y_{i}, y_{j}\right)$ linearized equations of state were used, where $y_{v}$ is an indirectly measured parameter; $y_{i}, y_{j}$ are directly measured parameters. In one-dimensional model of stratified environment (e.g. during the vertical probing of hydrophysical field fine structure) we have

$$
Y_{i}(z, t)=\iiint H_{i}\left(\xi_{1}, \xi_{2}, \xi_{3}\right) x_{i}\left(z-\xi_{3}\right) d \xi_{1} d \xi_{2} d \xi_{3}+\varepsilon_{i}(t),
$$

where $x_{i}$ is the values of $i$ physical quantity at the measuring channel input; $z$ is a depth; $\varepsilon_{i}(t)$ is a self-noise of $i$-th measuring channel; $t$ is a time.

Numerical modeling of the meter was carried out for equilibrium averaging of the field in the volumes of sensors presented in the form of circular cylinders with their different $L_{1}, L_{2}$ heights, relation of their $r_{1}, r_{2}$ radii, orientations of $\varphi_{1}, \varphi_{2}$ axes and $h$ spatial spacing. The errors were assessed as the differences between the directly or indirectly measured state parameters and their model values:

$$
\delta x_{v}\left(r_{i}, r_{j}, L_{i}, L_{j}, h, \varphi_{1}, \varphi_{2}, z, t\right)=y_{v}\left(y_{i}, y_{j}\right)-x_{v}\left(x_{i}, x_{j}\right) .
$$


In the perfect meter with completely compatible volumes of spatial averaging performed by the sensors, these differences are equal to zero.

When analyzing the errors, the model field distributions over the depth in the form of two layers under condition of hydrostatic stability were used. It is revealed that the cause of false emissions at the indirectly measured parameter reconstructed profiles is an incomplete compatibility of spatial averaging volume of directly measured parameter sensors. At the same time, the characteristics of equivalent meter spatial averaging of indirectly measured state elements will be different depending on the fact which field parameter is calculated. Fine structure reconstruction errors of indirectly measured parameters are critical to spatial separation of sensor averaging volumes and they have an asymmetrical nature relating to the boundary of layers.

Reconstruction errors of directly and indirectly measured parameters depend on sensor orientation in the field under study. When there is an increase of the ratio of the maximum averaging volume dimension to the minimum one, the requirements of stabilization of sensor axis orientation also increase. When these dimensions are commensurable, spatial averaging characteristics become closer to the isotropic sensor characteristics and orientation requirements can be reduced.

The increase of spatial resolution of hydrophysical field meters is one of the most important problems during the development of modern facilities of marine environment small-scaled structure research. This problem is solved by the optimal combination of sensor geometrical dimension reduction technique (for instance, through the multiple signal reflection on the base) and formation of nonequilibrium spatial averaging function (a priori method) with a subsequent input effect renewal (reconstruction) which is performed by means of corresponding mathematical procession of meter output signal (a posteriori method). The usage of optical and acoustic sensors with radiation focusing [18] is one of the ways of nonequilibrium spatial averaging function formation. The advantage of focusing method consists in the possibility of effective implementation of sensor spatial characteristic anti-noise correction in the domain of scales which are smaller than its geometric dimensions. This is due to the fact that the noises of meter occur after the spatial filtering (the increase of high spatial frequencies). In [6, 18] the possibility of HPMI spatial resolution increase (which is necessary, for instance, during the microstructure experimental research) had been studied through the example of focusing sensor of speed of sound (made in the form of open stable axisymmetric confocal spherical resonator) using the numerical methods.

A possible variant of measuring method implementation. Now we are to consider Fig. 2, where the structure of optical-acoustic apparatus implementing the above described method of liquid physical properties [12] (in particular of the seawater) by means of simultaneous light velocity and sound velocity measurements in the unified environment volume is shown schematically. The apparatus contains an electronic acoustic velocity meter 1 and reciprocating transducer 2 (made from piezoceramic, for example) with the optically mirror sound-radiating surface 3 . The transducer 2 is electrically connected with the meter 1. A unified effective volume of spatial averaging, carried out by physical field sensor in a liquid, is denoted by position 4. At the $L$ distance from the PHYSICAL OCEANOGRAPHY NO. 2 (2016) 
electroacoustic transducer 2 in parallel to its radiating surface 3 and coaxially to it optically transparent sound reflector the window 6 (made, for example, from quartz or sapphire) is mounted, and sound reflection occurs from its surface 5 . Furthermore, the apparatus comprises an optical-electronic meter 7 of light velocity in a liquid (refraction index), e.g. a laser interferometer. Optical axis of its actuating arm coincides with the acoustic axis of electroacoustic transducer 2 . The parameters of transducer 2 and meter 7 are selected so as to make effective cross sections of light and sound beams equal and compatible, as well as to make their axes coincide at the single measurement base $L$. In Fig. 2 an effective diameter of beams is marked by $D$. The distance $L$ forms a single base of sound velocity and light velocity meters. The meters 1 and 7 are connected to the calculator 8 (microprocessor with an interface) where directly and indirectly measured required parameters of the marine environment thermodynamic state are calculated in real time. The data (required for calculation) on pressure is obtained either from the separated pressure meter or transducer 2, according to the engineering solution described in [13].

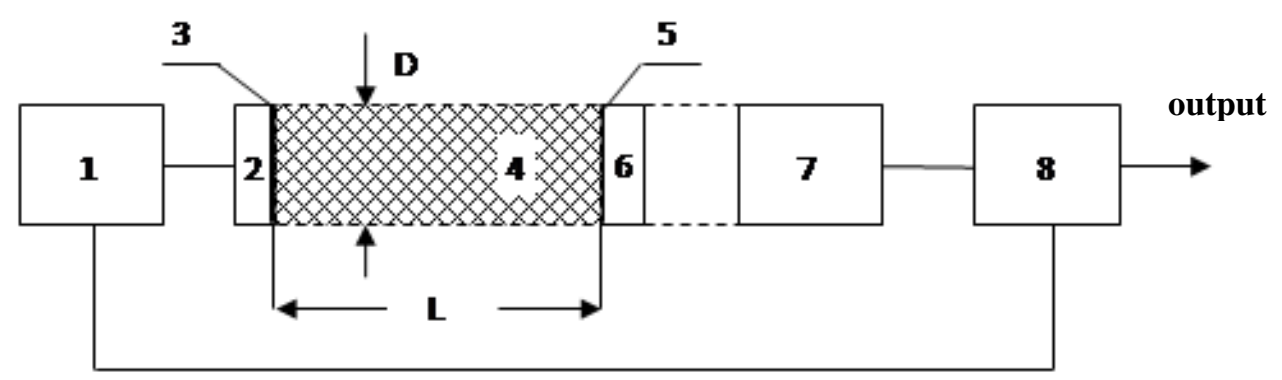

Fig. 2. Block diagram of compatible hydrophysical optical-acoustic sound and light velocity meter

The apparatus operates the following way: electronic sound velocity meter 1 (for example, pulse-cyclic or time-of-flight one) generates an electric impulse which excites the transducer 2 (piezoelectric one, for example). It transforms electric oscillations into mechanic ones which, propagating from its radiating surface 3 in the volume 4 of liquid under study, reflect from surface 5 of window 6 and return to the reversible converter 2. Here the ultrasonic oscillations are transformed back into the electric signal and get into the meter 1 where the sound velocity measurement at the base $L$ in the volume 4 takes place. Simultaneously, the optical-electronic meter 7 of refractive index with specified and stable light wave length (the Michelson optical interferometer, for instance; one of its arms is formed by the window 6 , the volume 4 of liquid under study and the surface 3 as a mirror) radiates a light beam. It runs through the window 6 , then through the volume 4 of the liquid under study, reflects from the optically mirror surface 3 and through the window 6 returns to the meter 7 where the determination of the refraction index at the $L$ base takes place. $L$ base geometric length is stabilized by the known methods or is directly measured (in order to eliminate mechanic and heat effect) in the additional arm by the same laser interferometer continuously and simultaneously during the measurements. It is also taken into account in $C$ and $C_{l}$ 
calculations [2 - 5]. According to the $X_{i}=X_{i}\left(C, C_{l}, P\right)$ expression, in the calculator 8 (along with the directly measured $C$ and $C_{l}$ parameters) the required parameters of marine environment thermodynamic state (such as density, salinity, temperature, conductivity, compressibility etc.) are calculated.

The advantage of the promising optical-acoustic meter is a high consistency (validity) of measurement results caused by well "flow ability" of the combined sensor and by its "bodiless". We should point out the following specifics of opticalacoustic meter: the necessity of correct light source radiation wavelength selection and the requirements for the stability of the light source radiation frequency. The minimum of coefficient of light attenuation in the environment and its low variability (in $0.6-0.65 \mu \mathrm{m}$ area, for instance) may be the criterion for the selection of optimal light wavelength. The requirements for radiation frequency stability are determined by the value of $\left(\partial / \partial_{l}\right)$ derivative where $f_{l}$ is a light source frequency. From $[1,5]$ it follows that for refractive index precision measurements the relative instability of monochromatic light radiation frequency (providing by the laser) should not exceed $\sim 10^{-6}$. An issue of single base $L$ optimal dimension selection is very important. On the one hand, it must meet the requirements for spatial resolution and fast response necessary for the given measuring task, and on the other, along with the optimization of $C$ and $C_{l}$ meter parameters, it must meet the requirements for achieving the highest threshold sensitivity of both optical and acoustic channels.

Measurement error assessments. Let us assess the errors of directly and indirectly measured marine environment thermodynamic state parameters by the promising compatible optical-acoustic hydrophysical meter. For this end, within the framework of seawater binary model, we are to use the known empirical dependences $[1-5]$ which interlink the directly measured $C, n, P$ parameters with the primary $T, S, \rho$ parameters of water state:

$$
C=C(T, S, P), \quad n=n(T, S, P), \quad \rho=\rho(T, S, P) .
$$

From these equations we obtain the formulas for calculation of indirectly measured parameters:

$$
T=T(C, n, P), \quad S=S(C, n, P), \quad \rho=\rho(C, n, P),
$$

where $C, n, P$ are measured by compatible optical-acoustic apparatus.

Let us represent the directly measured parameters as a sum of useful signal and instrumental noises (errors) reduced to the inputs of $C, n, P$ channels:

$$
C(t)+\varepsilon_{c}(t), \quad n(t)+\varepsilon_{n}(t), \quad P(t)+\varepsilon_{p}(t) .
$$

We form a correlation matrix from these summands. Assuming $C(t)=$ const, $n(t)=$ const, $P(t)=$ const and also uncorrelated of instrumental self-noise of the channels, we obtain (with zero time shifts) an expression for indirectly measured $X_{i}$ parameter random errors (trace of correlation matrix):

$$
\sigma_{x}^{2}=\left(\partial X_{i} / \partial C\right)^{2} \sigma_{c}^{2}+\left(\partial X_{i} / \partial n\right)^{2} \sigma_{n}^{2}+\left(\partial X_{i} / \partial P\right)^{2} \sigma_{p}^{2},
$$

where $\sigma_{c}^{2}, \sigma_{n}^{2}, \sigma_{p}^{2}$ are the dispersions of $\varepsilon_{c}(t), \varepsilon_{n}(t), \varepsilon_{p}(t)$ instrumental self-noises of $C$, $n, P$ measuring channels. 
To assess the errors of $X_{i}$ parameters (indirectly measured by optical-acoustic meter) according to the expression (2), the approximate values of the first partial derivatives of equation (1) determined by the [1 -5] data for mean $T, S, P$ values are represented in the table.

Partial derivatives of equations (1)

\begin{tabular}{c|cccc}
\hline$X$ parameter & $\partial X / \partial C$ & $\partial X / \partial n$ & $\partial X / \partial P$ \\
\hline$T, \mathrm{~K}$ & $\sim 0.3 \mathrm{~K} \cdot \mathrm{s} / \mathrm{m}$ & $1 \cdot 10^{4} \mathrm{~K} / \mathrm{rel}$. u. & $1 \cdot 10^{-8} \mathrm{~K} / \mathrm{Pa}$ \\
$S, \mathrm{psu}$ & $0.8 \mathrm{psu} \cdot \mathrm{s} / \mathrm{m}$ & $5 \cdot 10^{3} \mathrm{psu} / \mathrm{rel}$. u. & 0 \\
$\rho, \mathrm{kg} / \mathrm{m}^{3}$ & $-0.07 \mathrm{~kg} \cdot \mathrm{s} / \mathrm{m}^{4}$ & $2.7 \cdot 10^{3} \mathrm{~kg} /\left(\mathrm{m}^{3} \cdot\right.$ rel. u. $)$ & $4.4 \cdot 10^{-7} \mathrm{~kg} /\left(\mathrm{m}^{3} \cdot \mathrm{Pa}\right)$ \\
\hline
\end{tabular}

Here is a model example. With the really reached initial random errors of separately directly measured parameters of $\sigma_{c}=1 \cdot 10^{-3} \mathrm{~m} / \mathrm{s}, \sigma_{n}=1 \cdot 10^{-7}$ rel. u., $\sigma_{p}=1 \cdot 10^{3} \mathrm{~Pa}$, according to (2), we obtain the assessment of root-mean-square deviations (RMSD) of directly measured $\sigma_{T} \approx 1 \cdot 10^{-3} \mathrm{~K}$ temperature. We obtain RMSD assessments for indirectly measured salinity and density in the same way: $\sigma_{s} \approx 1 \cdot 10^{-3}$ psu and $\sigma_{\rho} \approx 1 \cdot 10^{-3} \mathrm{~kg} / \mathrm{m}^{3}$ or $\sim 1 \cdot 10^{-3}$ rel. u. As it can be seen, relative errors of directly and indirectly measured parameters are commensurable, and it is caused, mostly, by $\sigma_{n}$ error effect. Therefore it is desirable to improve $n$ measurement channel. Such threshold sensitivity indices of compatible opticalacoustic meter are sufficient to carry out the modern hydrophysical research, in particular in the Arctic basin where the effect of seawater desalination by river runoff is strong.

When calculating fluctuations and errors of indirectly measured state parameter absolute values (1), we use the arithmetic sum

$$
d X=(\partial X / \partial C) d C+(\partial X / \partial n) d n+(\partial X / \partial P) d P,
$$

where $\mathrm{dC}, \mathrm{dn}, \mathrm{dP}$ are deviations from the mean values or error non-excluded systematic components of directly measured parameters. Their minimum values are determined by standard base accuracy level.

Peculiarities of optical-acoustic meter graduation. One of modern metrology progressive trends is reference standard base decentralization in order to improve its quality and to maintain the uniformity of measurements. This is due to to the fact that hydrophysical measurement accuracy requirements in oceanography constantly increase approaching the accuracy of primary standards (for instance, in WOCE and TOGA programs). It is possible to create (on the basis of opticalacoustic method) a special combined primary standards of light velocity $C_{l}$ and sound velocity $C$ in transparent liquids with the reference to easily reproducible uniform absolute bench mark - light velocity in vacuum adopted as the world fundamental physical constant $\left(C_{\mathrm{vac}}=299792458 \mathrm{~m} / \mathrm{s}\right.$ accurately). It should be noted that the dimensions of these three physical quantities $\left(C, C_{l}, C_{\mathrm{vac}}\right)$ are the same $(\mathrm{m} / \mathrm{s})$. The single ideal measure (light velocity in a vacuum, where the absorption and frequency dispersion of light are absent and there is no dependence 
on temperature and pressure affecting the vessel with vacuum) automatically solves the problem of reference standard base complete decentralization of such meters and, from the meteorological point of view, fundamentally eliminates the obstacles to further improvement of these hydrophysical measuring instruments. Synchronous graduation of precision optical-acoustic meters of liquid thermodynamic state will allow us to develop regional equations of thermodynamic state and to revise experimentally the existing seawater state equations (including TEOS-10 (UNESCO)) for their further clarification.

Optical-acoustic probe benefit consists in the possibility of simultaneous calibration and graduation of all measuring channels in a pure distilled water. Pure distilled water is rather accessible standard material, its thermodynamic characteristics are well-studied, standardized and they can be easily reproduced with high accuracy and validity in a decentralized way. To calibrate the existing CTD-probes, the expensive and scarce solutions of normal seawater are required. The parameters of these solutions can be also studied with a high accuracy by optical-acoustic method. It is necessary to remind that distilled water is a singlephase and single-component liquid $(l=1, m=1)$. Its thermodynamic state is uniquely determined by any pair of directly measured parameters $(k=2)$, including the sound and light velocities. The same applies to other pure liquids.

Conclusion. Implementation of the proposed promising optical-acoustic method in the working hydrophysical measuring instruments, as well as the graduation method implementation, should allow us to consider them as an alternative to traditional hydrological CTD-probes. Moreover, it will be possible to perform a complexation of these measuring instruments with the modern CTDsystems in order to increase the number of independent directly measured state parameters aiming to clarify the existing state equations and to develop the regional ones (which take into account, for instance, the concentrations of hydrogen sulfide, methane, dispersed phase etc.). The complete usage of all useful information contained in such correct synchronous initial data should provide (on the basis of complexation) in situ obtaining of the best, valid, reliable and consistent assessments of marine environment thermodynamic state parameters in a wide range of temperatures and pressures (depths).

\section{REFERENCES}

1. Ivanov, A., 1978, "Vvedenie v okeanografiyu [Introduction to oceanography]”, Moscow, Mir, 576 p. (in Russian).

2. Babij, V.I., 1983, "Melkomasshtabnaya struktura polya skorosti zvuka v okeane [Small-scale structure of sound velocity field in the ocean]”, Leningrad, Gidrometeoizdat, 200 p. (in Russian).

3. Arhipkin, V.S., Dobrolyubov, S.A., 1998, “Osnovy termodinamiki morskoj vody”, Moscow, Dialog-MGU, 154 p. (in Russian).

4. Popov, N.I., Fedorov, K.N. \& Orlov, V.M., 1979, “Morskaya voda [Seawater]”, Moscow, Nauka, 327 p. (in Russian).

5. Bramson, M.A., Krasovskiy, E.I. \& Naumov, B.V., 1986, “Morskaya refraktometriya [Marine refractometry]”, Leningrad, Gidrometeoizdat, 247 p. (in Russian). 
6. Babiy, V.I., 2009, "Problemy i perspektivy izmereniya skorosti zvuka v okeane [Problem and prospects of sound velocity measuring in the ocean]”, Sevastopol, ECOSI-Gidrofizika, 142 p. (in Russian).

7. Lazaryuk, A.Yu., 2008, “Ob inertsionnosti datchikov temperatury i elektroprovodnosti CTDzondov [On inertance of CTD-probe sensor temperature and conductivity]”, Okeanologiya, no. 6, pp. 936-939 (in Russian).

8. Levtsov, V.I., Trokhan, A.M. \& Korolev, A.I. [et al.], 1989, “Modul'naya izmeritel'naya sistema dlya issledovaniya skalyarnykh gidrofizicheskikh poley okeana [Modular measuring system for investigation of hydrophysical scalar fields in the ocean]”, Metrologiya gidrofizicheskikh izmereniy, NPO VNIIFTRI, pp. $43-55$ (in Russian).

9. Babiy, V.I., Babiy, M.V., 1989, “Interferentsionnyy refraktometr [Interference refractometer]”, Patent USSR, no. 1453265.

10. Babiy, V.I., Babiy, M.V., 1990, “Ustroystvo dlya izmereniya skorosti zvuka v zhidkostyakh i gazakh [An apparatus for sound velocity measuring in fluids and gases]”, Patent USSR, no. 1538057.

11. Babiy, V.I., Babiy, M.V., 1986, “Sposob opredeleniya pokazatelya prelomleniya zhidkosti [A method for determining the refractive index of liquid]", Patent USSR, no. 1402066.

12. Babiy, V.I., Babiy, M.V., 1986, "Sposob izmereniya fizicheskikh svoystv zhidkostey $i$ ustroystvo dlya ego osushchestvleniya [Method for measuring the physical properties of liquids and an apparatus for its implementation]”, Patent USSR, no. 1239586.

13. Babiy, V.I., Babiy, M.V., 1986, “Ustroystvo dlya izmereniya raspredeleniya skorosti zvuka v zhidkosti [An apparatus for measuring the sound velocity distribution in a liquid]", Patent USSR, no. 1424453.

14. Babiy, V.I., Rodionov, A.A., 2014, "Spektral'nye otnosheniya signal/shum v gidrofizike i gidroakustike [Spectral signal/noise relations in hydrophysics and hydroacoustics]", Tr. XII Vserossiyskoy konferentsii Prikladnye tekhnologii gidroakustiki i gidrofiziki, Saint Petersburg, Nestor-Istoriya, pp. 335-337 (in Russian).

15. Babiy, V.I., Rodionov, A.A., 2014, "Fluktuatsii gidrofizicheskikh poley, obuslovlennye akusticheskimi shumami okeana [Hydrophysical field fluctuations caused by acoustic noises of the ocean]”, Dokl. RAN, no. 1, pp. 106-110 (in Russian).

16. Babiy, V.I., Babiy, M.V., 2004, "O nizkochastotnoy fil'tratsii signala $v$ gidrofizicheskikh izmeritelyakh skorosti zvuka [On signal low-pass filtering in hydrophysical meters of sound velocity]", Sistemy kontrolya okruzhayushchey sredy. Sredstva i monitoring, pp. 70-72 (in Russian).

17. Babiy, V.I., Babiy, M.V., 1994, "Matematicheskoe modelirovanie izmeriteley sostoyaniya morskoy sredy [Mathematical modeling of marine environment state meters]", Mezhdunarodnyy nauchno-tekhnicheskiy seminar Morskoe i ekologicheskoe priborostroenie. Sbornik trudov, Sevastopol, MGI NAN Ukrainy, pp. 14-17 (in Russian).

18. Babiy, V.I., Babiy, M.V. \& Zav'yalov, D.D., 1995, “Matematicheskoe modelirovanie fokusiruyushchikh pervichnykh izmeritel'nykh preobrazovateley [Mathematical modeling of focusing primary measuring transducers]”, Mezhdunarodnyy nauchno-tekhnicheskiy seminar Morskoe i ekologicheskoe priborostroenie. Sbornik trudov, Sevastopol, MGI NAN Ukrainy, pp. 84-85 (in Russian).

19. Babiy, V.I., Rodionov, A.A. \& Babiy, M.V., 2015, “Perspektivnyy optiko-akusticheskiy metod izmereniya parametrov termodinamicheskogo sostoyaniya morskoy sredy [Promising opticalacoustic method for measuring the parameters of marine environment hydrophysical state]", Tr. VIII Mezhdunarodnoy konferentsii Sovremennye problemy optiki estestvennykh sred (ONW-2015), Saint Petersburg, LEMA, pp. 254-259 (in Russian).

20. Babiy, V.I., Babiy, M.V. \& Rodionov, A.A., 2015, "Pokazateli kachestva izmereniy gidrofizicheskikh poley okeana [Quality indicators of the ocean hydrophysical field measurements]”, Sovremennye metody i sredstva okeanologicheskikh issledovaniy. Materialy XIV Mezhdunarodnoy nauchno-tekhnicheskoy konferentsii (MSOI-2015), vol. 1, pp. 48-53 (in Russian). 